\title{
VERBAL CHARACTERISTICS OF ADJECTIVES IN HAKHA CHIN
}

\author{
July, 2019 \\ Jillian Danaher \\ Indiana University Department of Linguistics
}

\begin{abstract}
This paper will present a few items of interest regarding adjectives in the Tibeto-Burman language Hakha Chin, which has approximately 165,000 speakers worldwide (Simons and Fennig, 2018). Using Fiona McLaughlin's methodology of comparing adjectival verbs and non-adjectival verbs in Wolof (McLaughlin, 2004), data will be presented comparing adjective and verb structures in Hakha Chin in an intransitive predicate construction, in a comparative construction, in a superlative construction, in questions, in negative constructions, and in relative clauses. This data will establish adjectives in Hakha Chin as being more verb-like than noun-like, and will place Hakha Chin in adjective class I, category 1, according to the classifications set by Robert Dixon (Dixon, 2004). This paper will conclude with a brief discussion of the role that adverbs may play in the adjectival verb phrases of Hakha Chin.
\end{abstract}

Key Terms - Hakha Chin, Hakha Lai, Lai Holh, Adjective, Adjective Classes, Stative Verbs, Verb-like Adjectives, Adjectival Verbs, Verbal Adjectives

\section{INTRODUCTION}

In their paper Adjectives in Lai (2012), George Bedell and Lalremzami Chinzah argue that adjectives in Hakha Chin are a subcategory of verbs. They claim that, "it is clear that they should be regarded as a subcategory of verbs rather than as an independent category. There is really only one characteristic of Lai adjectives: what we called the adjectival construction. Otherwise, they share the characteristics of Lai verbs" (13, Bedell and Lalremzami). In contrast, Robert Dixon states on page 9 of his book Adjective Classes: A Cross-Linguistic Typology that, "just as all languages have distinguishable classes of noun and verb, so all languages have a distinguishable adjective class" (2004). The implication is that even when adjectives act similarly to verbs, they will still form their own distinct class. This is borne out in data from Wolof, which has adjectival verbs that act almost exactly the same as non-adjectival verbs except within relative clauses, where they act uniquely (McLaughlin, 2004). For this reason, it is important to establish exactly how adjectival verbs pattern in Hakha Chin in order to fully understand its verb classes. The point investigated in this paper is to prove whether or not Hakha Chin adjectives pattern like verbs, and if so, do they pattern exactly the same or do they form their own similar-yet-distinct category. 


\section{Indiana Working Papers in South Asian Languages and Cultures}

Section 2 provides information about how adjectives tend to be structured in the world's languages. Section 3 discusses the methodology used to determine how Hakha Chin adjectives are structured, and section 4 presents the data gathered using this methodology. Finally, section 5 discusses the verb-like structure of Hakha Chin adjectives and presents remaining questions on the subject.

\section{BACKGROUND}

In Adjective Classes: A Cross-Linguistic Typology, Robert Dixon states that, "just as all languages have distinguishable classes of noun and verb, so all languages have a distinguishable adjective class" (2004, pg. 9). He defines these adjective classes based on their grammatical properties. They are divided into two different types of adjective classes (2004, p.14):

(I) Verb-like adjectives which can function as an intransitive predicate.

(II) Non-verb-like adjectives which can function as a copula complement.

He then states that these adjective classes can be further classified into four more specific categories (p.15):

1. Adjectives that are verb-like \& non-noun-like (these belong in class I)

2. Adjectives that are noun-like \& non-verb-like (these belong in class II)

3. Adjectives that are both verb-like \& noun-like (these belong in class I)

4. Adjectives that are non-verb-like \& non-noun-like (these belong in class II)

It is noted that adjectives in Tibeto-Burman languages (the language family to which Hakha Chin belongs) tend to be in class I (Dixon, 2004). This means that they must then also belong to either category 1 or category 3 . The way in which adjectives can function as either nouns or verbs will be further clarified in section 3 .

\section{METHODS}

The data were collected with the help of Zai Sung, who is a native speaker of Hakha Chin and student at Indiana University. Preliminary data indicated that Hakha Chin adjectives pattern with type I languages, so it was necessary to find another language that is type I and compare it with Hakha Chin. Wolof was chosen due to the similarities between Wolof's adjectives and verbs. In her article Is There an Adjective Class in Wolof?, Fiona McLaughlin illustrates that adjective and verbs act exactly the same in Wolof, except within relative clauses (2004). Since Wolof's adjectives pattern similarly to its verbs, Wolof can be classified as a type I language. McLaughlin gives a table on page 261 which illustrates her method for determining the behavior of verb-like adjectives in Wolof. Her table is pictured Table 1. This chart was used as a basis to create an elicitation list that would test the similarities of adjectives and clearly non-adjectival verbs in Hakha Chin. 


\section{Indiana Working Papers in South Asian Languages and Cultures}

Table 1: "A comparison of the relevant characteristics of adjectives and non-adjectival Verbs" (Mc Laughlin, 2004, p. 261).

\begin{tabular}{|c|c|c|c|}
\hline Reference & Characteristic & Adjectives & Non-adjectival Vs \\
\hline$\$ 2.4$ & Function as copula complement & No & No \\
\hline$\$ 2.4$ & Function as intransitive predicate & Yes & Yes \\
\hline$\$ 2.4$ & Function as transitive predicate & Yes & Yes \\
\hline$\$ 2.2$ & Inflect for tense & Yes & Yes \\
\hline$\$ 2.2$ & Inflect for aspect & Yes & Yes \\
\hline$\$ 2.2$ & Inflect for mood & Yes & Yes \\
\hline$\$ 2.1$ & Take verbal extensions & Yes & Yes \\
\hline$\$ 2.3$ & $\begin{array}{l}\text { Participate in syntactically encoded } \\
\text { focus system }\end{array}$ & Yes & Yes \\
\hline$\$_{1.0}, \$_{3.0}, \$_{3.2}$ & $\begin{array}{l}\text { Relativizer separated out from defin- } \\
\text { ite article in definite simple relative } \\
\text { clauses }\end{array}$ & Yes & No \\
\hline$\$ 3 \cdot 3$ & $\begin{array}{l}\text { Relativizer separated out from defin- } \\
\text { ite article in definite extended relative } \\
\text { clauses }\end{array}$ & No & No \\
\hline$\$ 3.5$ & $\begin{array}{l}\text { Adjacent to modified noun in relative } \\
\text { clauses }\end{array}$ & Yes & No \\
\hline$\$ 4.4$ & Take adverbs & Yes & Yes \\
\hline$\$ 4.4$ & Can form a compound & Yes & Yes \\
\hline$\$ 4.3$ & Comparatives using gën & No & No \\
\hline$\$ 4.3$ & Comparatives using gëna & Yes & Yes \\
\hline$\$ 4.1, \$ 4.2, \$ 4.4$ & Take coverbal ideophones & Some & Some \\
\hline$\$ 4.0, \$ 4.5$ & Open class & Yes & Yes \\
\hline
\end{tabular}

Table 1 lists characteristics relevant to the morphology and syntax of Wolof verbs, such as their inflection and whether or not they function as a copula or intransitive predicate, and then states whether or not an adjective behaves that way and compares that to the behavior of nonadjectival verbs. The first two characteristics in this table are what places Wolof adjectives in Dixon's adjective class I. The first line shows that neither adjectives nor non-adjectival verbs can function as a copula complement. This is the defining characteristic of class II adjectives, which rules out the possibility of Wolof having non-verb-like adjectives. Adjectives are considered to behave like verbs if they can function as an intransitive predicate. The second line in Table 1 states that like non-adjectival verbs, adjectives in Wolof can function as an intransitive predicate. Since this is the defining characteristic of class II adjectives, Wolof adjectives must then be placed in class I.

Although adjectives in Wolof are certainly verb-like, Table 1 also shows that they do not behave in the exact same manner as non-adjectival verbs. When it comes to simple relative clauses, non-adjectival verbs allow the relativizer to be separated from the definite article, while nonadjectival verbs do not. Similarly, adjectives can "remain adjacent to modified noun in relative 


\section{Indiana Working Papers in South Asian Languages and Cultures}

clauses," which non-adjectival verbs cannot do. This means that even though Wolof adjectives behave like verbs, they form a separate class of verbs that is distinct from non-adjectival verbs.

Section 4 uses Table 1 as a basis for comparing adjectival verbs with non-adjectival verbs in Hakha Chin. It starts by establishing that adjectives in Hakha Chin can function as an intransitive predicate and continues by comparing adjectives and non-adjectival verbs in a comparative construction, in a superlative construction, in questions, in negative constructions, and in relative clauses. These comparisons show that while Hakha Chin adjectives are verb-like, they are distinctly separate from non-adjectival verbs.

\section{DATA}

This section will present data which show Hakha Chin adjectives to be class II adjectives. It starts by establishing that adjectives in Hakha Chin can function as an intransitive predicate, which classifies Hakha Chin adjectives as being verb-like. Since Wolof adjectives remain distinct from non-adjectival verbs despite being verb-like, this section continues by comparing adjectives and non-adjectival verbs in a comparative construction, in a superlative construction, in questions, in negative constructions, and in relative clauses in order to establish Hakha Chin adjectives not only as verb-like, but also as their own distinct verb class.

First it is important to determine whether or not Hakha Chin adjectives belong in class I, which is verb-like, or class II, which is non-verb-like. The defining characteristic of a verb-like adjective is an adjective that can function as an intransitive predicate. The following sentences compare a Hakha Chin adjective, as in (1), to an intransitive verb, as in (2). The elements that are of particular interest in these two phrases have been bolded. Appendix A provides an explanation for each grammatical gloss.

(1) ma vok hi 2a-nan tok

DEM pig DEI 3SG-big [very]

'This pig is big'

(2) ma vok hi 2a-2it

DEM pig DEI 3SG-sleep

'This pig slept'

The bolded morphemes indicate that adjectives take the same prefix as intransitive verbs, which shows agreement in number and person with the subject. This establishes Hakha Chin adjectives as being verb-like. Hakha Chin can then be classified as a language with class I adjectives. Furthermore, the speaker never gave an example of an adjective that did not occur as the verbal element in a verb phrase. When asked if the adjective could take away the agreement prefix shown in phrases (1) and (2) and replace it with a copula construction, the speaker replied that it could not. This implies that adjectives in Hakha Chin are non-noun-like in the way that they cannot function as a copula complement and can only function as verbs. This further classifies Hakha Chin adjectives as being class II, type 1 according to Dixon's model. 


\section{Indiana Working Papers in South Asian Languages and Cultures}

However, while the adjectival verb and the non-adjectival verb themselves are similar in structure, the verb phrases are not. (1) requires the presence of the adverbial intensifier tok 'very' at the end of the verb phrase, where (2) does not. This means that although Bedell and Chinzah (2012) were correct in claiming that adjectives in Hakha Chin pattern as verbs, they do not behave in exactly the same way. This difference in the structures of adjectival verb phrases and nonadjectival verb phrases remains the same when clauses are conjoined and when they are inflected for number, tense, and aspect. A comparison of adjectival verb phrases, as in (3), and nonadjectival verb phrases, as in (4), in conjoined phrases is given below. Note that the adjectival verb phrase in (3) uses tak 'very' and foun 'very' at the end of the adjectival verb phrases as opposed to tok which was seen in (1). Foun, tak, and tok can all be glossed as 'very' and serve the same function as adverbial intensifiers. The elements that are of particular interest have been bolded.

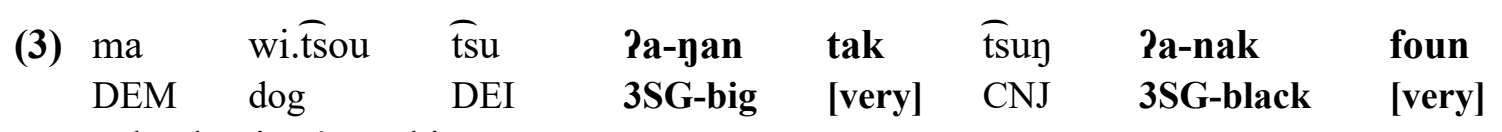

'The dog is big and is black'

$\begin{array}{lllll}\text { (4) wi.tsou } & \text { zol } & \text { Pa-Pe? } & \text { tsuy } & \text { Pa-Pit } \\ \text { dog } & \text { food } & \text { 3SG-eat } & \text { CNJ } & \text { 3SG-sleep }\end{array}$

'The dog ate and slept'

In (3), both adjectival verbs in the conjoined phrase require an adverbial intensifier, while the non-adjectival verbs do not. This suggests that adjectival verbs require some sort of particle to end the verb phrase and that not just any word or morpheme can fill that role. Some sort of adverbial element must follow the adjective in an adjectival verb phrase. This can be illustrated again in phrases that are inflected for number. (5.1-5.2) give examples of adjectival verb phrases in the singular and in the plural, and (6.1-6.2) give examples of non-adjectival verb phrases in the singular and in the plural.
(5.1) sa.ve?
(tsu)
Pa-kur-(Pa)-zun ${ }^{1}$
tak
rabbit (DEI) 3SG-quick-(3SG)-quick [very]
'The rabbit is quick'

(5.2)
sa.ve?-(pol)
Pun-kur-(Pa)-zun
tok
rabbit-(PL)
3PL-quick-(3SG)-quick
'The rabbits are quick'

[very] PL

\footnotetext{
${ }^{1}$ Note here that the adjective "quick" appears to be a compound word in this speaker's (Zai's) lexicon. Because of its status as the second base in the compound, the inflectional agreement on the second verb base does not seem to be required, nor does it seem to inflect the way that Hakha Chin verbs normally do. For the purposes of this paper, the peculiarities of this particular construction will not be discussed.
} 


\section{(6.1) sa.ve? 2a-?it \\ rabbit 3SG-sleep \\ 'The rabbit slept'}
(6.2) sa.ve?-(pol) Pun-?it noa
rabbit-(PL) 3PL-sleep PL
'The rabbits slept'

Even when the plural marker has been added in (5.2), the adjective still requires an adverbial intensifier to directly follow it. This is once again different from the non-adjectival verb phrases in (6.1) and (6.2), which do not require that anything follows the verb. This holds true again for phrases that are marked for tense. (7) gives an adjectival verb which is marked for the future tense, and (8) gives an example of a non-adjectival verb that is marked for the future tense. Note that (7) uses tokte 'very', which is semantically largely indistinguishable from tok, tak, and foun and functions as an adverbial intensifier.

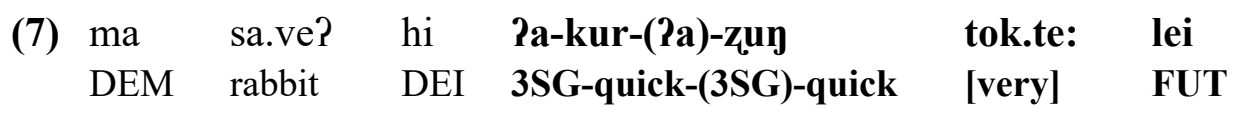

'The rabbit will be quick'

$\begin{array}{lllll}\text { (8) ma } & \text { sa.ve? } & \text { hi } & \text { 2a-Pit } & \text { lei } \\ \text { DEM rabbit } & \text { DEI } & \text { 3SG-sleep } & \text { FUT } \\ \text { 'The rabbit will sleep' } & & \end{array}$

Again, (7) shows that the adverbial intensifier must directly follow the adjective in an adjectival verb phrase, even when the phrase is marked for tense. This remains true for phrases that are marked for aspect. An example of an adjectival verb phrase which is marked for the perfective aspect is given in (9), and a non-adjectival verb phrases marked for the perfective aspect is given in (10).

$\begin{array}{lllllll}\text { (9) ma } & \text { sa.ve? } & \text { hi } & \text { tsu } & \text { 2a-kur-2a-zun } & \text { tok } & \text { tsan } \\ \text { DEM rabbit } & \text { DEI } & \text { TOP } & \text { 3SG-quick-3SG-quick } & \text { [very] } & \text { PRF } \\ \text { 'The rabbit is already quick' } & & & \end{array}$

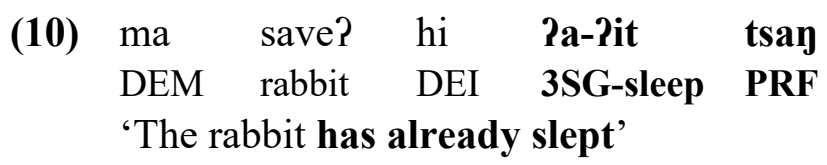

The adjectival verb phrase given in (9) is practically the same as the adjectival verb phrase given in (7), save for the choice in adverbial intensifier and the choice in the tense or aspect. Once again, these adjectival verb phrases remain different from non-adjectival verb phrases only in that 
an adverbial intensifier is required after an adjective. This indicates that plurality, tense, and aspect are not indicated in Hakha Chin with adverbs, but rather with some other type of particle.

When sentences already contain adverbs, there appears to be no difference in structure between adjectival verb phrases and non-adjectival verb phrases. (11) gives an adjectival verb phrase with an adverbial intensifier intentionally elicited, which can be compared to the intentionally intensified non-adjectival verb phrase in (12). The elements that are of particular interest have been bolded.

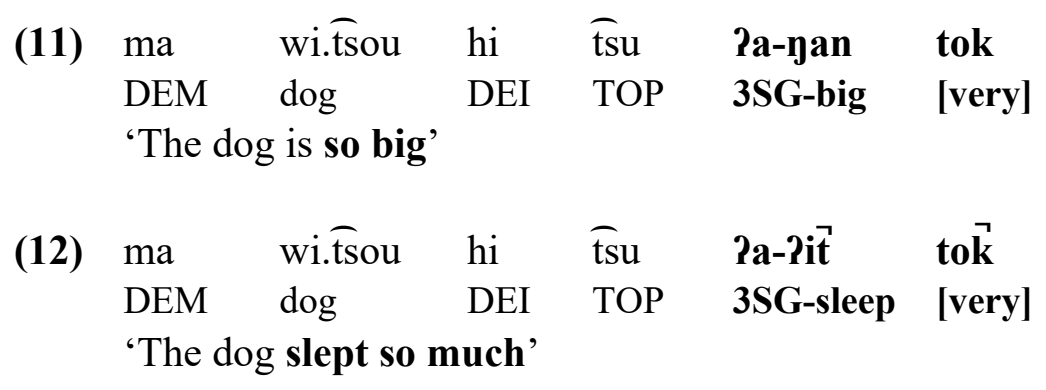

As we can see from the bolded elements, the difference between the two verb phrases disappears once an adverbial element is intentionally added to it. This also occurs true in comparatives, superlatives, questions, negation, and relative clauses, which potentially gives insight into how these types of clauses are formed in Hakha Chin.

Comparatives eliminate the need for adverbial intensifiers in an adjectival verb phrase. This is shown in (13), which has the same structure as the non-adjectival phrase in (14). The elements that are of particular interest have been bolded.

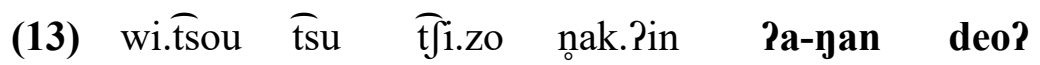 dog DEI cat COORD 3SG-big COMP
'The dog is bigger than the cat'

$\begin{array}{llllll}\text { (14) wi.tsou } & \text { tsu } & \text { tfi.zo } & \text { nak.Pin } & \text { 2a-Pit } & \text { deo? } \\ \text { dog } & \text { DEI cat } & \text { COORD } & \text { 3SG-sleep } & \text { COMP } \\ \text { 'The dog slept more than the cat' } & & \end{array}$

The role of a required adverbial intensifier at the end of an adjectival verb phrase is filled by the comparative marker in (13). This is different from expressions of plurality, tense, and aspect. This suggests one of two things: 1. either that comparative phrases in Hakha Chin are formed with adverbs, or 2. that adjectives do not require an adverbial element, but rather something that serves as a sort of semantic intensifier.

The adjectival phrase given in (15) adds strength to the former suggestion that comparatives might be formed in Hakha Chin using an adverb. (15) gives an example of an adjectival verb phrase with the question marker added, while (16) gives a non-adjectival phrase with the question marker. 


\section{Indiana Working Papers in South Asian Languages and Cultures}

(15)

$\begin{array}{lllll}\text { ma } & \text { vok } & \text { hi } & \text { ?a-yan } & \text { ma: } \\ \text { DEM } & \text { pig } & \text { DEI } & \text { 3SG-big } & \text { Q }\end{array}$

'Is this pig big?'

(16)

$\begin{array}{lllll}\text { ma } & \text { vok } & \text { hi } & \text { Pa-Pit } & \text { ma: } \\ \text { DEM } & \text { pig } & \text { DEI } & \text { 3SG-sleep } & \mathbf{Q}\end{array}$

'Did this pig sleep?'

The structure of the two verb phrases is identical in (15) and (16), which means that the interrogative construction seems to function more closely like the comparative constructions given in (13) and (14), rather than like the construction for plurality, tense, and aspect. The same is also true for negative constructions. A negative adjectival verb phrase is given in (17), while a negative non-adjectival verb phrase is given in (18).

$\begin{array}{lllll}\text { ma vok hi } & \text { 2a-yan } & \text { lou } \\ \text { DEM pig } & \text { DEI } & \text { 3SG-big } & \text { NEG } \\ \text { 'This pig is not big' } & & \end{array}$

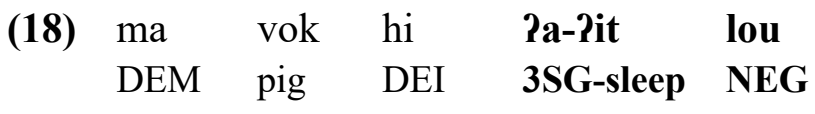

'This pig did not sleep'

The adjectival verb phrase in (17) holds the same structure as the non-adjectival verb phrase in (18), which is similar to comparative, interrogative, and negative constructions. Since both the question marker and the negative marker can fill the role of adverbial intensifier at the end of a non-adjectival verb phrase, it seems more likely that these phrases are expressed using an adverbial element in Hakha Chin, rather than adjectival verb phrases requiring a semantic intensifier.

Adjectives also do not take an adverbial intensifier when they are placed in a relative clause. This is shown in (19), where the construction for an adjectival verb phrase in a relative clause is the same as the structure for the non-adjectival verb phrase in (20).

(19)

$\begin{array}{llll}\text { tffi.zou } & \text { Pa-zuy } & \text { mi } & \text { ka-mou: } \\ \text { cat } & \text { 3SG-white } & \text { REL } & \text { 1SG-see }\end{array}$

'I saw the white cat'

(20)

$\begin{array}{llll}\text { tfi.zou } & \text { 2a-thni } & \text { mi } & \text { ka-mu: } \\ \text { cat } & \text { 3SG-run } & \text { REL } & \text { 1SG-see } \\ \text { 'I saw the cat running' }\end{array}$

The adjectival verb phrase behaves differently when it is placed in a main, such as in (1) or (3), as opposed to the relative clause given here in (19). This suggests that adjectives only require an adverbial element to follow it when it is in a main clause. This leaves some room for 


\section{Indiana Working Papers in South Asian Languages and Cultures}

interpretation when it comes to superlative. Superlatives in Hakha Chin are formed using relative clauses. As such, adjectival verbs do not require adverbial intensifiers. This is demonstrated in (21) below, which can be compared with the non-adjectival verb phrase given in (22).

$\begin{array}{lllll}\text { ma wi.tsou } & \text { hi } & \text { Pa-nan } & \text { pik-mi } & \text { Pa-si: } \\ \text { DEM dog } & \text { DEM } & \text { 3SG-big } & \text { SUPL-REL } & \text { COP } \\ \text { 'The dog is the biggest' } & & & \end{array}$

(22)

$\begin{array}{llllll}\text { ma wi.tsou } & \text { hi } & \text { 2a-Pit } & \text { pik-mi } & \text { Pa-si: } \\ \text { DEM dog } & \text { DEM } & \text { 3SG-sleep } & \text { SUPL-REL } & \text { COP } \\ \text { 'The dog slept the most' } & & & \end{array}$

As of yet, it is unclear why the superlative requires a relative clause in Hakha Chin. It is also unclear as to whether or not the role of adverbial element is filled in the adjectival verb phrase by the superlative marker, which would be similar to the comparative construction given in (13), or if the adverbial element is no longer needed because the adjectival verb is no longer in the main clause. This is certainly an interesting area for further research.

\section{CONCLUSION}

Example 1 established that adjectives in Hakha Chin can function as intransitive verbs. This classifies Hakha Chin as a type I language in Dixon's adjectival class system. Since TibetoBurman languages tend to be type I (Dixon, 2004), we can conclude that adjectives in Hakha Chin pattern similarly to adjectives in its related languages. Examples 3 and 4 showed that adjectives in Hakha Chin can function as an intransitive predicate and cannot function as a copula complement, meaning that Hakha Chin adjectives are both verb-like and non-noun-like, and are therefore class I, type 1 adjectives. Hakha Chin is therefore in the first of Dixon's four categories for adjective classes. However, examples 1 and 2 indicated that although Bedell and Chinzah (2012) were correct in claiming that adjectives in Hakha Chin do pattern like verbs, they form their own distinct subcategory that behaves differently.

In addition to allowing us to classify adjectives in Hakha Chin, this paper has also raised some new questions. In clauses where an adverb is already present, adjectival verbs in Hakha Chin use the exact same construction as intransitive verbs. In fact, the only instance in which adjectival verb phrases have a different structure than their non-adjectival counterparts is when there is no particle present at the end of the phrase. When this occurs, adjectival verbs take an adverbial intensifier to compensate, where non-adjectival verbs do not. Do adjectival verbs in Hakha Chin simply require a particle to be present at the end of the verb phrase? Or do they specifically require an adverb? If they do specifically require an adverb, the lack of an adverbial intensifier in sentences (13), (15), (17), (19), and (21) implies that comparatives, superlatives, questions, negations, and relative clauses in Hakha Chin are already constructed using adverbs. In order to know if the verb final particle is really necessary, more phrases need to be elicited 
with more adjectival verbs, more non-adjectival verbs, and more speakers. In order to know if comparatives, superlatives, questions, negations, and relative clauses are constructed using adverbs, more analysis needs to be done on these types of clauses in Hakha Chin.

\section{REFERENCES}

Bedell, G. (2001) “The Syntax of Deixis in Lai,” Linguistics of the Tibeto-Burman Area, 24(2), 157-171.

Chinzah L., and Bedell G. (2012) "Adjectives in Lai", Paper presented at the thirty-fourth All India Conference of Linguistics, Shillong.

Dixon, R. M. W. (2004) "Adjective Classes in Typological Perspective" in Adjective Classes: A Cross-Linguistic Typology, 1-49.

McLaughlin, F. (2004) "Is There an Adjective Class in Wolof?", in Adjective Classes: A Cross-Linguistic Typology, 242-262.

Peterson, D. A. (2003) "Hakha Lai", in The Sino-Tibetan languages, ed. Graham Thurgood \& Randy J. LaPolla, 409-426.

Simons, Gary F. and Charles D. Fennig (eds.). (2018) Ethnologue: Languages of the World, Twenty-first edition. Dallas, Texas: SIL International. Online version; http://www.ethnologue.com. 
Indiana Working Papers in South Asian Languages and Cultures

Appendix A: Glossing abbreviations

The abbreviations used in glosses are as follows:

3SG - third person singular

3PL - third person plural

CNJ - conjunction

COMP - comparative

COORD - coordinative

DEM - demonstrative

DEI - deictic marker

FUT - future tense marker

NEG - negative/negation

PL - plurality marker

PRF - perfective marker

$\mathrm{Q}$ - interrogative marker

REL - relative

SUPL - superlative

TOP - topic

PRF - perfect 